\title{
Characterization and Inheritance of a New Source of Resistance to Fusarium oxysporum f. sp. melonis Race 1.2 in Cucumis melo
}

\author{
R. Herman and R. Perl-Treves, The Mina and Everard Goodman Faculty of Life Sciences, Bar-Ilan University, \\ Ramat-Gan 52900, Israel
}

\begin{abstract}
Herman, R., and Perl-Treves, R. 2007. Characterization and inheritance of a new source of resistance to Fusarium oxysporum f. sp. melonis race 1.2 in Cucumis melo. Plant Dis. 91:1180-1186.

Four physiological races $(0,1,2$, and 1.2) of Fusarium oxysporum f. sp. melonis, causal agent of Fusarium wilt in melons, have been described. Whereas resistance against each of the races 0,1 , and 2 is encoded by a single dominant $R$-gene, resistance against the fourth race, FOM 1.2, is polygenically inherited and was recently characterized in the cultivar Isabelle. In the present study, we report on an independently derived source of resistance to race 1.2, the Israeli breeding line BIZ. The disease response of BIZ seedlings was compared with two susceptible genotypes, Line 33 and PI 414723, and the partially resistant genotype, Isabelle, at increasing concentrations of inoculum. BIZ exhibited near-complete resistance to race 1.2, even at inoculum levels of $10^{6}$ spores per $\mathrm{ml}$ and root wounding, indicating that such resistance is stronger than that in Isabelle. Although in previous studies the $\mathrm{F}_{1}$ hybrids between BIZ and the sensitive lines displayed full resistance in the field, in the present study they were susceptible under artificial inoculation conditions that involve high inoculum concentrations of $10^{6}$ spores per $\mathrm{ml}$ and root wounding; under intermediate inoculum levels $\left(10^{5}\right.$ and $5 \times 10^{5}$ spores per $\left.\mathrm{ml}\right)$ they were partially resistant. Segregation of the resistance response in the $F_{2}$ and back-cross- 1 progeny from a cross between BIZ and PI 414723 supported a model in which two complementary, recessive genes are required to obtain full resistance. While the fungus was shown to colonize root tissue of both resistant and susceptible lines, colonization was markedly lower in the resistant plants, and the fungus was nearly absent from upper stem segments.
\end{abstract}

Additional keywords: wilt disease

Fusarium wilt causes severe damage to melons in Israel and elsewhere around the world. This soilborne disease is caused by Fusarium oxysporum Schlechtend. f. sp. melonis Snyd. \& Hans., which is specific to Cucumis melo. The pathogen penetrates through the root system, invades the vascular elements, and causes wilting and plant death $(10,11,15,27)$. The use of resistant cultivars and grafting on resistant rootstocks $(14,30)$ are very effective in controlling the disease in melons. However, the rise of new physiological races represents a major threat to resistant cultivars.

Isolates of $F$. oxysporum f. sp. melonis have been classified into four pathogenic races, FOM $0,1,2$, and 1.2, according to their ability to infect a known set of differential melon genotypes (25). Race 1.2 was further divided into two subraces: $1.2 \mathrm{y}$, which causes leaf yellowing before wilt-

Corresponding author: R. Perl-Treves E-mail: perl@mail.biu.ac.il

* The $e$-Xtra logo stands for "electronic extra" and indicates that Figures 1 through 5 appear in color in the online edition.

Accepted for publication 24 April 2007.

doi:10.1094/PDIS-91-9-1180

(C) 2007 The American Phytopathological Society ing, and $1.2 \mathrm{w}$, nonyellowing strains where wilting occurs without prior yellowing symptoms. Race $1.2 \mathrm{y}$ has been reported in Israel. The genetic control of Fusarium wilt resistance has been elucidated in a few resistant genotypes that serve as sources of resistance in melon breeding. Resistance to races 0,1 , and 2 is monogenic and dominant. The Fom-1 gene, originally identified in cultivar Doublon, confers resistance to races 0 and 2, whereas the Fom-2 gene, originally identified in CM 17187 , confers resistance to races 0 and $1(22,23,25)$. Another gene, Fom-3, controls resistance to races 0 and 2 in cultivar Perlita FR, but data about its possible allelism with Fom-1 is controversial $(5,24,32)$. Resistance to the fourth race, 1.2 , is more complex and appears to be controlled by multiple recessive genes. Such resistance was described in the Far Eastern line Ogon 9 and introgressed into Isabelle, a partially FOM 1.2resistant cultivar $(18,19,26)$. Isabelle was crossed to 'Giallo di Paceco', an Italian landrace, and the resulting $F_{1}$ was subjected to parthenogenesis, haploid embryo rescue, and chromosome doubling. Two doubled-haploid lines, Nad-1 and Nad-2, exhibited strong resistance to FOM 1.2 (8). Perchepied and Pitrat (19) studied the inheritance of FOM 1.2 resistance using a recombinant inbred line (RIL) population derived from the cross between Isabelle and FOM 1.2-susceptible cultivar Védrantais. They concluded that resistance was polygenic, with most RILs skewed toward the susceptible parent. In a subsequent study, the same 120 RILs were subjected to full marker-assisted analysis of quantitative trait loci (QTL). Nine QTLs for FOM 1.2 resistance were resolved, and their map-positions in five linkage groups were reported (18).

Fields in the Bet Netofa Valley in northern Israel harbor all four races of $F$. $o x$ ysporum f. sp. melonis $(4,13)$, and this area is therefore exploited by melon breeders to screen their breeding lines and hybrids. A new FOM 1.2-resistant line, BIZ, was developed through selection of breeding material by J. Katan and breeders from the seed company Zeraim Gedera. The selected genotype was self-pollinated for eight generations, and resistance was stabilized to homozygosity. An $\mathrm{F}_{1}$ hybrid, Adir, derived by crossing BIZ with a nonresistant counterpart, displayed good field resistance to all four races of $F$. oxysporum $\mathrm{f}$. sp. melonis at three geographical locations in Israel (Tamra, Bet Netofa, and Jennin), whereas genotypes that were resistant only to FOM 0,1 , and 2 but not race 1.2 were severely affected (Fig. 1). Adir also was used as a rootstock for the susceptible melon cultivar Ophir, and provided good protection from Fusarium wilt (12). However, the nature of FOM 1.2 resistance in the BIZ genotype has not been thus far characterized. This study was designed to elucidate the inheritance and characteristics of such resistance in comparison to that previously described in Isabelle melon, which exhibits partial resistance to FOM 1.2 (19). Such characterization will assist breeders in achieving a higher, more durable resistance by combining multiple genes, each conferring partial resistance, or by selecting alleles with the strongest effect in critical QTLs.

\section{MATERIALS AND METHODS}

Plant material. Melon lines BIZ and 33 were developed at Zeraim Gedera Ltd., Israel. Line 33 is a typical Ananas dessert melon line resistant to FOM 0,1 , and 2 but susceptible to race 1.2 , whereas BIZ, a Galia-type melon line, is resistant to all four races (Zeraim Gedera Inc., our unpublished data). Seeds of BIZ and 33 were provided by Zeraim Gedera. Seeds of Isabelle were provided by M. Pitrat, INRA, Avignon, France. PI 414723 (16) is an 
Indian landrace of poor horticultural value that has been widely used as a source of resistance genes and as a mapping parent, due to the frequent DNA polymorphism between this accession and commercial genotypes $(6,20,29)$. It is resistant to FOM 0 and 1 but susceptible to 2 and 1.2. The four genotypes-BIZ, Isabelle, line 33, and PI 414723-were grown under standard greenhouse conditions in the spring and autumn seasons in Israel. They were crossed to obtain $F_{1}$ hybrids and the subsequent $\mathrm{F}_{2}$ and $\mathrm{BC}_{1}$ progenies required for the analysis of inheritance. Table 1 summarizes the genotypes and crosses used in this study.

Fungal strains. FOM 1.2 isolate $18 \mathrm{H}$ from the Bet Netofa Valley, Israel, was obtained from Prof. J. Katan, Hebrew University of Jerusalem. The fungus was cultured at room temperature on $2 \%$ potato dextrose agar (PDA) medium (Duchefa Bioch., The Netherlands). About 10 days before plant inoculation, fungal mycelium was subcultured on yeast-extract medium $(0.5 \% \mathrm{wt} / \mathrm{vol}$ yeast extract, Difco, France, $0.5 \% \mathrm{wt} / \mathrm{vol}$ Bacto-Peptone, Difco, $2 \%$ $\mathrm{wt} / \mathrm{vol}$ glucose, $2 \% \mathrm{wt} / \mathrm{vol}$ agar, Tal-Ron, Israel. $0.25 \mathrm{~g} / \mathrm{liter}$ chloramphenicol, Duchefa Bioch.). For inoculation, agar plates with dense, sporulating fungal mycelium were macerated in a blender, and the spore concentration was determined using a hemacytometer. Tap water was added to obtain the desired concentration ( 0.1 to $1 \times 10^{6}$ spores per $\left.\mathrm{ml}\right)$.

Fusarium inoculation. Melon seeds were germinated in 200-ml disposable pots with a 3 peat: 1 perlite mixture, and seedlings were grown at 20 to $27^{\circ} \mathrm{C}$. After 9 to 10 days, when the first true leaf emerged, the seedlings were carefully removed from the pots, and their roots were rinsed in tap

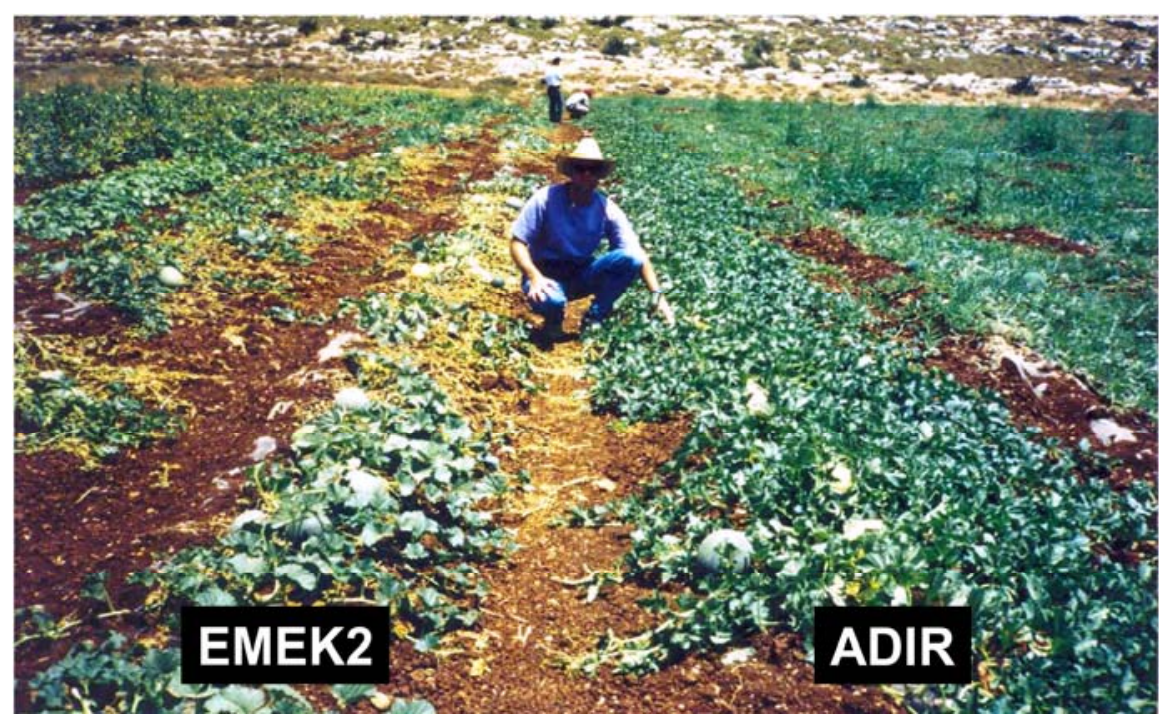

Fig. 1. Field trial in soil infested with all four races of Fusarium oxysporum f. sp. melonis (FOM). Right plot: Adir, a hybrid between BIZ and a FOM 1.2-susceptible line that is resistant to races 0,1 , and 2. Left plot: Emek2, a hybrid that is resistant to FOM races 0, 1, and 2 but susceptible to race 1.2. Approximately 100 plants per row were grown in summer 1996. Nearly all Adir plants reached maturity, whereas over $50 \%$ of Emek2 wilted before harvest. water, trimmed to $3-\mathrm{cm}$ length, and immersed in the freshly prepared fungal suspension for $3 \mathrm{~min}$. The inoculated seedlings were replanted, four plants per pot, using a new pot with a similar potting mixture. Noninoculated plants were intom-free.

Evaluation of disease symptoms. Initial symptoms were observed 10 to 14 days postinoculation (dpi). Plants were observed periodically (every 1 to 5 days, depending on experiment) until 21 dpi. Plants were classified as either healthy, with no symptoms, or diseased, i.e., displaying leaf yellowing with some necrotic spots or wilting symptoms, stunting, or eventual death. The proportion of each class out of the total seedling number was calculated.

Tissue colonization by the fungus. To test which plant regions were invaded by FOM 1.2, infected seedlings (10 seedlings per genotype) were cut and surfacesterilized in $1 \%$ sodium hypochlorite for 1 min, followed by two rinses, 1 min each, in sterile water. The root, lower hypocotyls, middle-hypocotyl, and upper-hypocotyl explants were blotted on sterile filter paper for 1 to $2 \mathrm{~min}$ and placed on petri dishes $25^{\circ} \mathrm{C}$, to determine which parts of the plants were colonized.

Statistical analysis. Experiments that compared disease progression between inoculum concentration treatments in a range of genotypes were repeated twice. Standard errors of the percentage of diseased seedlings were computed as $100 \times[b$ $\times(1-b) / n]^{0.5}$, where $b$ is the proportion of a given class, and $n$ is the total number of plants (7). Area under the disease progress curve (AUDPC) was calculated according cluded as a control and remained sympwith PDA medium for 7 days at 20 to to Campbell and Madden (2). The tissuecolonization experiment was repeated three times, and the three experiments were analyzed as replicates. Percentage of colonized segments and standard deviations were calculated. In the inheritance analysis, the whole experiment was repeated twice using independently derived progenies from different seed lots, and segregation of healthy and diseased progeny in the $\mathrm{F}_{2}$ and $\mathrm{BC}_{1}$ populations (Table 1) was used to formulate alternative genetic models that were statistically tested using $\chi^{2}$ distributions.

\section{RESULTS}

Evaluation of resistance to FOM 1.2 in the parental lines and their hybrids. To determine the level of resistance of the BIZ genotype, an artificial inoculation method was used, which is considered a more severe test than field conditions. It involves uprooting of young-stage seedling, wounding, and exposure of the roots to very high concentrations of spores (up to 1 million spores per $\mathrm{ml}$ ). This method is used to screen breeding material for resistance to FOM 0,1 , or 2 , but it is considered too severe for use with FOM 1.2 on melon cultivar Isabelle. Thus, the FOM 1.2-resistant line, BIZ, along with susceptible genotypes Line 33 and accession PI 414723, were inoculated with FOM 1.2 at three different spore concentrations. Two $\mathrm{F}_{1}$ hybrids between BIZ and each of the two susceptible lines, PI 414723 and Line 33 , were tested as well. Figure 2 displays the proportion of diseased plants, with either yellowing or wilting symptoms, during 3 weeks postinoculation with different concentrations of FOM 1.2 spores. The AUDPC values are given as well, and represent the integrated progression of the disease over the whole period.

At the final scoring date, $45 \%$ of the susceptible Line 33 plants and $60 \%$ of PI 414723 were diseased when $10^{5}$ spores per

Table 1. Genotypes and crosses used in this study

\begin{tabular}{ll}
\hline $\begin{array}{l}\text { Parental } \\
\text { genotype }\end{array}$ & Resistance to FOM 1.2 \\
\hline BIZ & Resistant \\
PI 414723 & Susceptible \\
Line 33 & Susceptible \\
Isabelle & Partially resistant \\
Genetic cross & \\
(\# and generation) & Cross \\
\hline $1 \mathrm{~F}_{1}$ & PI $414723 \times \mathrm{BIZ}$ \\
$2 \mathrm{~F}_{1}$ & Line $33 \times \mathrm{BIZ}$ \\
$3 \mathrm{~F}_{1}$ & BIZ $\times$ Isabelle \\
$4 \mathrm{~F}_{2}$ & (PI 414723 $\times$ BIZ) $\times$ self \\
$5 \mathrm{BC}_{1}$ & (PI 414723 $\times \mathrm{BIZ)} \times \mathrm{BIZ}$ \\
$6 \mathrm{BC}_{1}$ & (PI $414723 \times \mathrm{BIZ)}$ \\
& $\times$ PI 414723 \\
\hline
\end{tabular}

${ }^{a}$ Fusarium oxysporum f. sp. melonis race 1.2.

${ }^{b}$ In each cross, the parent on the left was the female parent, and the one on the right was the pollen parent. 
$\mathrm{ml}$ were used (Fig. 2A). At an intermediate concentration of $0.5 \times 10^{6}$ spores per $\mathrm{ml}$ (Fig. 2B), 80 to $90 \%$ of these lines were diseased, whereas at $10^{6}$ spores per $\mathrm{ml}$ (Fig. 2C) disease progression appeared to be faster, based on visual evaluation of curve steepness and larger AUDPC values. At this inoculum concentration, all plants were wilted or dead. The resistant line BIZ was not affected at all by the two lower spore concentrations, and even with $10^{6}$ spores per $\mathrm{ml}$, only $\sim 10 \%$ of the plants were diseased. In repeated experiments, BIZ typically had between 0 and $15 \%$ diseased plants at the final scoring date. Low incidence of diseased plants from Fusarium-resistant genotypes has been often documented (31), and BIZ, which has been genetically stabilized by repeated self-pollination, is no exception. The two $\mathrm{F}_{1}$ hybrids from the crosses between BIZ and the sensitive genotypes (crosses 1 and
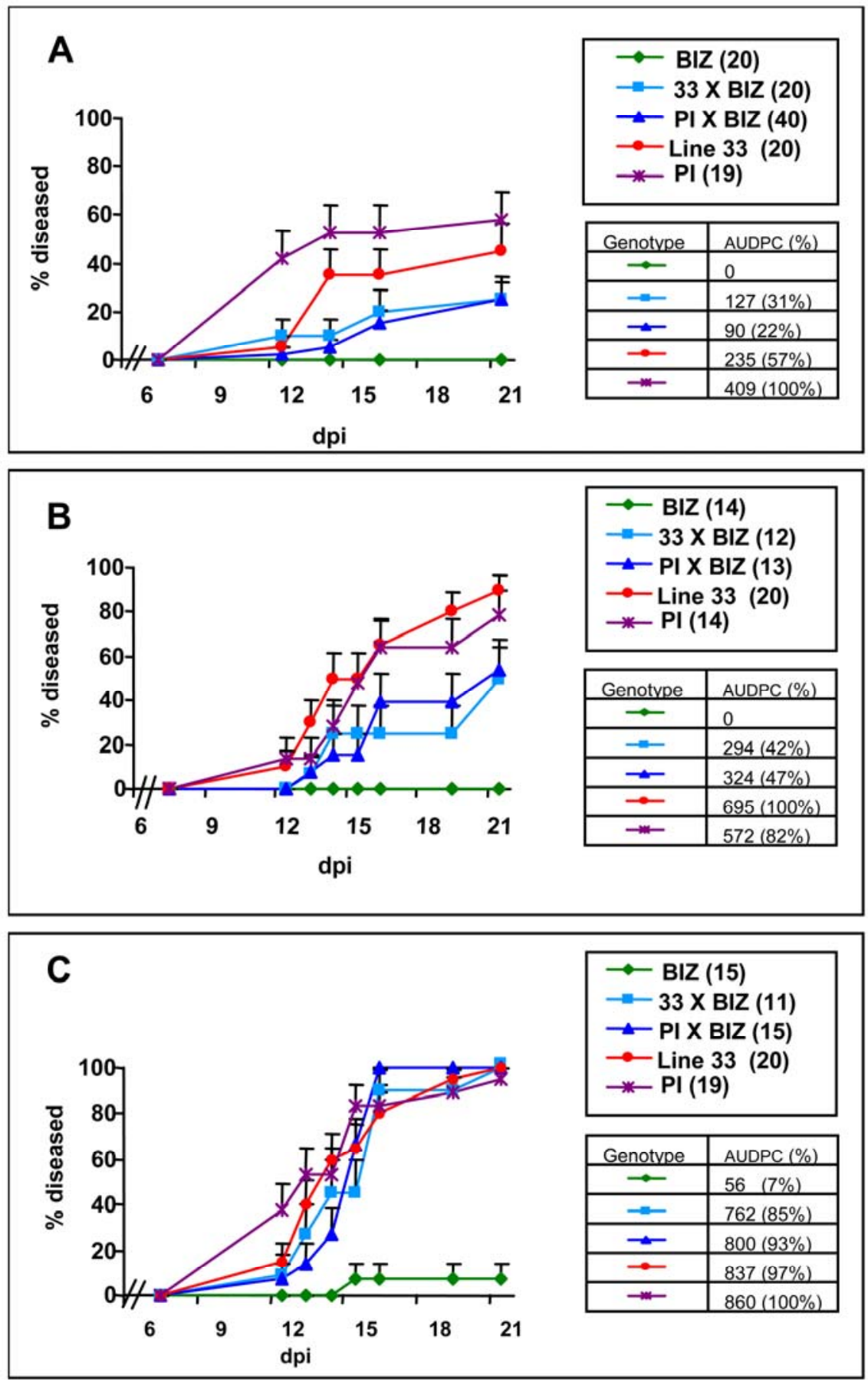

Fig. 2. Effect of three different inoculum levels on percent disease. A, $1 \times 10^{5}$ spores $/ \mathrm{ml} ; \mathbf{B}, 5 \times 10^{5}$ spores $/ \mathrm{ml} ; \mathbf{C}, 1 \times 10^{6}$ spores $/ \mathrm{ml}$. Legends indicate parental lines, hybrid genotypes, and in parentheses, the number of seedlings scored. Error bars express the standard error of diseased plant percentage values. For each genotype, area under disease progression curve (AUDPC) was calculated and expressed as percent diseased plants $\times$ days. In parentheses, relative AUDPC values are given as the ratio between a genotype's AUDPC and that of the most susceptible genotype. dpi $=$ days postinoculation.

2 , Table 1) displayed intermediate resistance with the $10^{5}$ and $5 \times 10^{5}$ spores per $\mathrm{ml}$ treatments (25 and $50 \%$ diseased plants at $21 \mathrm{dpi}$, respectively), and these values were significantly different from both the resistant and susceptible parents (Figs. 2A and B). All differences between the two $F_{1}$ hybrids and their parents were significant, except for the difference between the $F_{1}$ hybrids and Line 33 at the lowest concentration. When the AUDPC values of each curve were compared, the two $F_{1}$ hybrids stand out, having intermediate values with slower progression at the two lower spore concentrations, compared with the susceptible lines. Thus, at the lowest concentration (Fig. 2A), the $F_{1}$ hybrids had relative AUDPC values of 22 to $31 \%$ of those of the most susceptible line, whereas at the intermediate concentration the $F_{1}$ values were 42 to $47 \%$ of the most susceptible line (Fig. 2B). On the other hand, disease progression in both the $F_{1}$ and the sensitive lines at the highest inoculum concentration was similar, and the final score at $21 \mathrm{dpi}$ was the same, with nearly $100 \%$ diseased plants (Fig. 2C). The experiment was repeated twice with similar results.

Segregation of FOM 1.2 resistance. To determine the possible inheritance of FOM 1.2 resistance in the BIZ genotype, we examined the segregation of healthy and diseased progeny in two independent experiments (Table 2). The $\mathrm{F}_{1}, \mathrm{~F}_{2}$, and $\mathrm{BC}_{1}$ generations from the cross between $\mathrm{BIZ}$ and PI 414723 (Table 1) were inoculated with $10^{6}$ spores per $\mathrm{ml}$, along with the parental lines. The results at $21 \mathrm{dpi}$ were subjected to the $\chi^{2}$ test to analyze the possible mode of inheritance of the resistance trait (Table 2).

Nearly all plants of the parental PI 414723 line were diseased, whereas $10 \%$ or less of the BIZ line were diseased. In the $F_{1}$ progeny between these two lines (Cross 1, Table 1), the final proportion of diseased plants was 94\%. The progeny that resulted from back-crossing the $F_{1}$ hybrid to the susceptible parent, PI 414723 (Cross 6, Table 1), were susceptible, consistent with a recessive mode of inheritance. Only a single individual in each experiment was symptom-free and could probably be regarded as an "escape". In the other back-cross population (Cross 5, Table 1), obtained by pollinating the $\mathrm{F}_{1}$ hybrid with the resistant parent BIZ, 22 to $26 \%$ of the progeny were healthy and about $75 \%$ were diseased. This is consistent with a model suggesting that two recessive genes are necessary to obtain complete resistance, where the $\mathrm{BC}_{1}$ segregates in a 1:3 ratio of resistant plants: diseased plants, as confirmed by the $\chi^{2}$ test (Table 2). In the $\mathrm{F}_{2}$ progeny resulting from self-pollination of the $F_{1}$ hybrid (Cross 4, Table 1), only 8 of 145 and 15 of 173 plants in two different experiments were green and healthy, consis- 
tent with a $1: 15$ ratio predicted by the same model.

Comparison of the two sources of FOM 1.2 resistance, BIZ and Isabelle. The level of protection against FOM 1.2 determined by the BIZ genotype was compared with the partial resistance reported for cultivar Isabelle by Perchepied and Pitrat (19). Samples of BIZ, Isabelle, PI 414723, and two $F_{1}$ hybrids, PI $414723 \times$ $\mathrm{BIZ}$ and BIZ $\times$ Isabelle, were inoculated with FOM 1.2. We used two spore concentrations, $5 \times 10^{5}$ and $10^{6}$ spores per $\mathrm{ml}$. Disease progression was recorded over a 3-week period (Fig. 3). A sample of plants inoculated with $10^{6}$ spores per $\mathrm{ml}$, at 21 dpi, is shown in Figure 4. Out of 20 plants of line BIZ, two (10\%) became diseased at the lower inoculum level. At the highest inoculum level, only three plants were diseased $(15 \%)$. Cultivar Isabelle had a much higher amount of diseased plants at 21 dpi: 74\% following the lower inoculum treatment, and $94 \%$ at the higher inoculum level (Fig. 3). While the final score of diseased versus healthy plants was not substantially different between Isabelle and the two susceptible genotypes, disease progression in Isabelle was slower. Thus, the AUDPC values of Isabelle (about 70\%) were lower than those of PI 414723 (Fig. $3 \mathrm{~A}$ and $\mathrm{B}$ ). In a replicate experiment, $60 \%$ relative AUDPC values were recorded at the higher inoculum concentration (not shown). Moreover, most of the diseased Isabelle plants were yellow but still alive $21 \mathrm{dpi}$, as opposed to the susceptible lines, where most plants were dead at that time (Fig. 4)

The $\mathrm{F}_{1}$ hybrids between BIZ and Isabelle (represented in Figure 3 as two repli- cates from independent crosses) were not significantly different from Isabelle at any time-point and inoculum concentration. Nearly all plants were diseased at the conclusion of the high-inoculum treatment, and the AUDPC values were similar to those of Isabelle.

Plant colonization by FOM 1.2. To examine the relationship between resistance and presence of the pathogen in plant tissue, seedlings of PI 414723 and BIZ were inoculated with FOM 1.2 and, after 21 days, sections of root, lower hypocotyls, mid-hypocotyl, and upper hypocotyls were plated on sterile PDA plates and incubated at 20 to $25^{\circ} \mathrm{C}$. Seven days after plating, massive growth of $F$. oxysporum developed from all PI 414723 segments, including the upper hypocotyl. Root segments of BIZ were also colonized by the fungus, but the extent of colonization was somewhat smaller than with roots of the susceptible genotype (not shown). The two genotypes differed markedly in colonization of the stem by the pathogen. All hypocotyl segments (from either the upper, middle, or lower hypocotyl) of PI 414723 were colonized by the fungus, and the mycelium that emerged was dense and more intensely colored. Most of the lower-hypocotyl segments of BIZ (average $8.7 \pm 1.1$ out of 10 seedlings per replicate) were also colonized (Fig. 5), but the diameter and the density of the mycelial mass were markedly smaller than those of the mycelium that emerged from the susceptible line. The middle and upper segments were less populated with the fungus: only $2.7 \pm 1.1$ and $2.3 \pm 0.6$ out of 10 mid-stem and upper-stem explants, respectively, gave rise to mycelium.

\section{DISCUSSION}

This study demonstrates that under varying inoculation conditions, different levels of resistance are expressed. In breeding programs, selecting the proper conditions to screen for pathogen resistance is critical. Our studies show that inoculum concentration affects the response of the plants to the pathogen and indicate that, when trying to introgress BIZ alleles for FOM 1.2 resistance, a concentration of $10^{6}$ spores per $\mathrm{ml}$ is the most adequate. Lesser concentrations (Figs. 2 and 3) caused wilting and/or yellowing symptoms only in some of the plants. Under such inoculation conditions, many susceptible plants could escape infection and erroneously be designated as resistant (1). Using an aggressive inoculation protocol (wounding and immersing in a high concentration spore suspension) solves this problem, and we suggest that plants that remained healthy are probably homozygous for the major genetic elements underlying BIZ resistance. Thus, artificial inoculation with $10^{6}$ spores per ml enabled us to differentiate between a lower level of resistance that could be present in heterozygous genotypes, and the fully resistant homozygotes. Under such conditions, the $\mathrm{F}_{1}$ hybrids behave similarly to the sensitive lines, revealing a recessive behavior of the genes involved (Fig. 2C). Under the less severe inoculation regimes (Fig. 2A and $\mathrm{B})$, the $\mathrm{F}_{1}$ hybrids had an intermediate level of resistance, which could be accounted for by a partial-dominant mode of inheritance. Interestingly, under natural inoculation conditions in the open field (Fig. 1, our unpublished results), the $F_{1}$ hybrids between BIZ and susceptible

Table 2. Segregation of plant response, at 21 days postinoculation, to Fusarium oxysporum $\mathrm{f}$. sp. melonis race $1.2\left(10^{6}\right.$ spores per $\left.\mathrm{ml}\right)$ in the $\mathrm{F}_{2}$ population and two $\mathrm{BC}_{1}$ populations derived from the cross between PI 414723 (PI) and BIZ, as well as their parental lines

\begin{tabular}{|c|c|c|c|c|c|c|c|c|}
\hline \multirow{2}{*}{$\begin{array}{r}\text { Experiment }^{\mathrm{a}} \\
\text { Population }\end{array}$} & \multirow[b]{2}{*}{ Plant no. } & \multicolumn{2}{|c|}{ Observed } & \multicolumn{2}{|c|}{ Expected $^{\text {b }}$} & \multirow[b]{2}{*}{$\chi^{2}$} & \multirow[b]{2}{*}{$P$} & \multirow[b]{2}{*}{ df } \\
\hline & & Healthy & Diseased & Healthy & Diseased & & & \\
\hline \multicolumn{9}{|l|}{ A } \\
\hline BIZ & 36 & 33 & 3 & 36 & 0 & & & \\
\hline PI & 20 & 0 & 20 & 0 & 20 & & & \\
\hline $\mathrm{F} 1(\mathrm{PI} \times \mathrm{BIZ})$ & 16 & 1 & 15 & 0 & 16 & & & \\
\hline $\mathrm{F}_{2}$ & 173 & 15 & 158 & $11(1: 15)$ & 162 & 1.55 & 0.21 & 1 \\
\hline $\mathrm{BC}_{1}(\mathrm{PI} \times \mathrm{BIZ}) \times \mathrm{BIZ}$ & 98 & 25 & 73 & $24.5(1: 3)$ & 73.5 & 0.01 & 0.9 & 1 \\
\hline $\mathrm{BC}_{1}(\mathrm{PI} \times \mathrm{BIZ}) \times \mathrm{PI}$ & 59 & 1 & 58 & 0 & 59 & & & \\
\hline \multicolumn{9}{|l|}{ B } \\
\hline BIZ & 20 & 19 & 1 & 20 & 0 & & & \\
\hline PI & 20 & 1 & 19 & 0 & 20 & & & \\
\hline $\mathrm{F}_{1}(\mathrm{PI} \times \mathrm{BIZ})$ & 18 & 1 & 17 & 0 & 18 & & & \\
\hline $\mathrm{F}_{2}$ & 145 & 8 & 137 & $9(1: 15)$ & 136 & 0.12 & 0.73 & 1 \\
\hline $\mathrm{BC}_{1}(\mathrm{PI} \times \mathrm{BIZ}) \times \mathrm{BIZ}$ & 98 & 21 & 77 & $24.5(1: 3)$ & 73.5 & 0.67 & 0.41 & 1 \\
\hline $\mathrm{BC}_{1}(\mathrm{PI} \times \mathrm{BIZ}) \times \mathrm{PI}$ & 55 & 1 & 54 & 0 & 55 & & & \\
\hline \multicolumn{9}{|l|}{$A+B$} \\
\hline BIZ & 56 & 52 & 4 & 56 & 0 & & & \\
\hline PI & 40 & 1 & 39 & 40 & 0 & & & \\
\hline $\mathrm{F}_{1}(\mathrm{PI} \times \mathrm{BIZ})$ & 34 & 2 & 32 & 0 & 34 & & & \\
\hline $\mathrm{F}_{2}$ & 318 & 23 & 295 & $20(1: 15)$ & 298 & 0.48 & 0.49 & 1 \\
\hline $\mathrm{BC}_{1}(\mathrm{PI} \times \mathrm{BIZ}) \times \mathrm{BIZ}$ & 196 & 46 & 150 & $49(1: 3)$ & 147 & 0.24 & 0.62 & 1 \\
\hline $\mathrm{BC}_{1}(\mathrm{PI} \times \mathrm{BIZ}) \times \mathrm{PI}$ & 114 & 2 & 112 & 0 & 114 & & & \\
\hline
\end{tabular}

${ }^{a} \mathrm{~A}$ and $\mathrm{B}$ represent two independent experiments.

${ }^{\mathrm{b}}$ Data from each separate experiment and their combination were subjected to the chi-square test to evaluate the model of two complementary recessive genes that confer full resistance. 

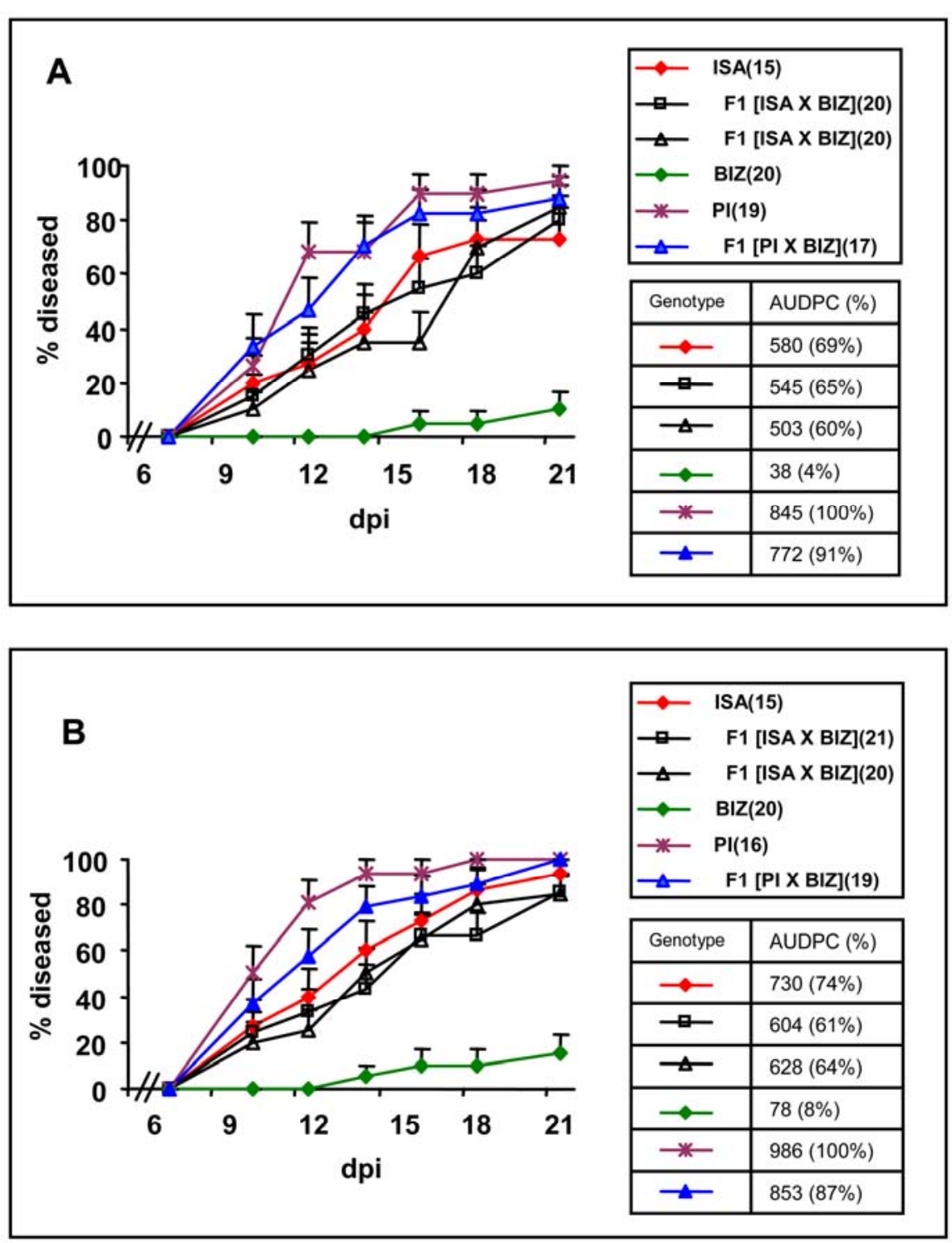

Fig. 3. Response of melon genotypes BIZ, Isabelle (ISA), PI 414723 (PI), and two $\mathrm{F}_{1}$ hybrids to Fusarium oxysporum f. sp. melonis race 1.2. A, Inoculation at $5 \times 10^{5} \mathrm{spores} / \mathrm{ml}$. B, Inoculation with $10^{6} \mathrm{spores} / \mathrm{ml}$. Legends indicate parental lines, hybrid genotypes, and in parentheses, the number of seedlings scored. For each genotype, area under disease progression curve (AUDPC) was calculated and expressed as percent diseased plants $\times$ days. In parentheses, relative AUDPC values are given as the ratio between a genotype's AUDPC and that of the most susceptible genotype. dpi = days postinoculation.

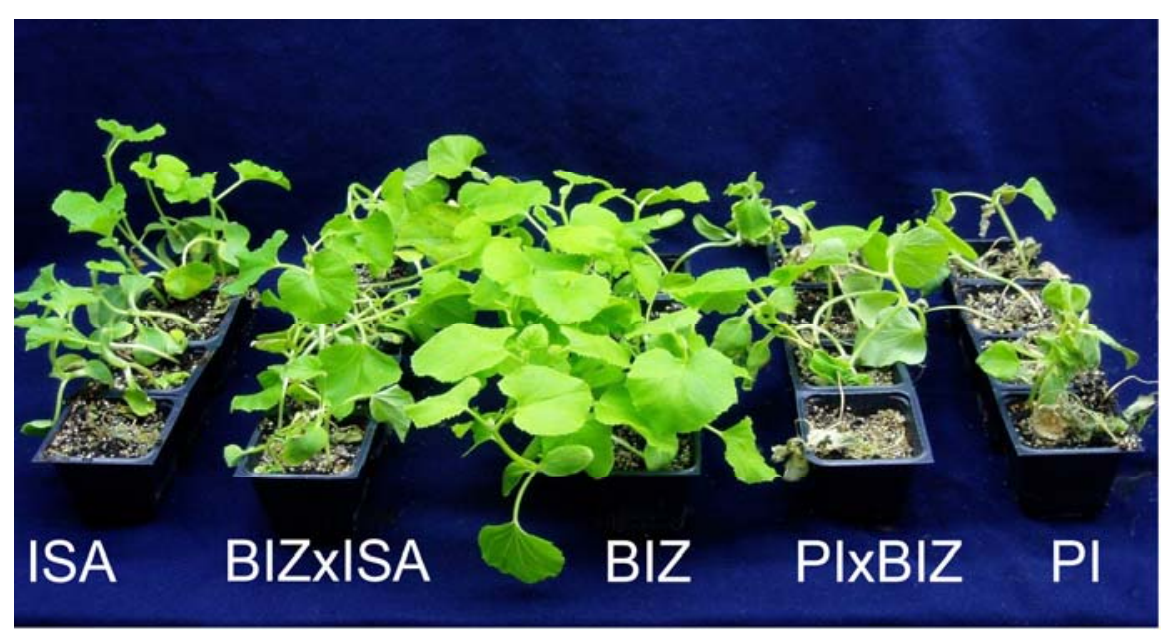

Fig. 4. Comparison of melon genotypes BIZ, Isabelle (ISA), PI 414723 (PI), and two $F_{1}$ hybrids, 21 days after inoculation with Fusarium oxysporum f. sp. melonis race $1.2\left(10^{6} \mathrm{spores} / \mathrm{ml}\right)$. breeding lines performed well, with approximately $95 \%$ symptomless plants. In the field, inoculum concentration could be substantially lower than in artificial inoculation, and the pathogen may be competing with other organisms in the rhizosphere, in particular other physiological races of Fusarium. Moreover, it has been shown that nonpathogenic Fusarium strains can cross-protect melons against FOM 1.2 (9). The $F_{1}$ that we used is resistant against races 0,1 , and 2 ; it could be that in the field these strains actually protected the $F_{1}$ hybrids. Other environmental differences between greenhouse and field conditions such as light intensity could also influence plant development and its response to pathogens, contributing to the different performance of a genotype under different conditions.

Thus, this study demonstrates that alleles encoding certain traits may behave as dominant, co-dominant, or recessive, depending on the environmental conditions or on the plant developmental stage. Chen and Line (3) reported on a developmental change in gene action regarding rust resistance genes in barley: the gene behaved as dominant based on the response of the first leaf, but appeared recessive on the basis of the second leaf. An early documentation of such changes was reported by Shiffriss (28) regarding fruit color inheritance in Cucurbita pepo. In that study, heterozygous plants manifested the characteristic of one parent in the beginning of the season and that of the other parent later, and this was termed "reversal of dominance" and attributed to a greater sensitivity of the heterozygote to environmental effects. It was therefore advised that genetic studies should monitor the expression of plant phenotypes in a few, rather than a single, developmental stages or environmental conditions. A dynamic concept of gene action is widely accepted when dealing with quantitative traits, where different sets of conditions often uncover different QTLs, and QTLs mapped in one year $\times$ location combination only partially overlap with those expressed in another experiment $(17,18,21)$. Thus, the same defense gene could elicit a response that completely protects all plants in one case, but only delays wilting, or protects the more vigorous ones, in a second case. A complete QTL analysis using a RIL population, where the same genotype can be replicated under different conditions, would help differentiate between these possibilities.

Our data suggest that FOM 1.2 resistance in BIZ is phenotypically distinct from that reported in cultivar Isabelle. The genetic relatedness between Isabelle, which derived its FOM 1.2 resistance from the Chinese accession Ogon 9, and our line BIZ, which originated from breeder's selection in Israel, is presently unknown. QTLs responsible for FOM 1.2 resistance 
in Isabelle have been mapped recently (18). BIZ definitely has a higher level of resistance, manifested under aggressive inoculation conditions (Figs. 3 and 4), whereas Isabelle only exhibits an intermediate level of resistance, manifested as a delayed progression of the disease; however, at 21 dpi the difference between Isabelle and the susceptible genotypes is greatly reduced. The difference between Isabelle and BIZ could be explained either by the presence of different loci for resistance in the two lines or by different alleles in the same locus. If the loci are different, one would expect the $F_{1}$ hybrid between BIZ and Isabelle to be completely susceptible, since under high inoculum pressure, resistance is recessive. However, the $F_{1}$ exhibits an intermediate level of resistance, similar to Isabelle (Fig. 3), suggesting that the R-loci of the two lines could overlap, with the BIZ-derived alleles behaving as recessive when confronted with the weaker Isabelle-derived alleles. Alternatively, the loci (or part of them) could be different but they interact, resulting in lower susceptibility in the $F_{1}$. Discriminating between these possibilities will require comparative mapping of the BIZ versus Isabelle-derived resistance using molecular markers.
In the study by Ficcadenti et al. (8), double-haploid lines originating from the cross Isabelle $\times$ Giallo di Paceco were screened for FOM 1.2 resistance, and two highly resistant lines were obtained, Nad-1 and Nad-2, that withstood high inoculum levels and root pruning. This could indicate that the level of resistance displayed by Isabelle can be improved by selecting for additional loci that significantly contribute to overall resistance.

We wished to determine whether the resistant plants were able to stop fungal invasion of their root or stem. Ficcadenti et al. (8) examined the tissues of inoculated susceptible and resistant plants for the presence of FOM 1.2. They found that the fungus was present in the hypocotyls of a small proportion of the resistant plants. In our study, FOM 1.2 was present in all tissue segments of the susceptible genotype PI 414723, but its presence in most BIZ seedlings was restricted to the roots and the lower hypocotyls (Fig. 5). Moreover, it appeared that mycelial growth from BIZ segments was moderate, suggesting that the amount of mycelium in the tissue could be smaller, compared with that of susceptible plants. Similar results were obtained by Horev (12), where Hemed melons that carry the Fom-1 gene were less colonized with FOM 2.

This study indicates that two complementary recessive genes are required for resistance under severe $\left(10^{6}\right.$ spores per $\left.\mathrm{ml}\right)$ inoculation conditions. Segregation analysis in the $\mathrm{F}_{2}$ and $\mathrm{BC}_{1}$ generations showed a $1: 15$ ratio of healthy plants in the $F_{2}$, and a $1: 3$ ratio in the resistant parent back-cross (Table 2). This indicates that complete resistance (healthy, green plants 21 days after severe inoculation) is controlled by two recessive genes, which we have designated fom $1.2 a$ and fom $1.2 b$. Healthy plants left to grow longer in pots (up to 35 dpi, data not shown) never developed wilt; BIZ-derived resistance was shown to effectively protect the plants also at the critical stage of fruit development in the field. In the susceptible class, we observed variation in disease symptoms that included wilted, dying plants as well as "survivors" with yellowing symptoms. Such variation could originate from heterozygosity of some progeny in one or two of the main loci, indicating that the two genes are not completely recessive. While two homozygous loci are required for resistance, heterozygosity could affect the level of susceptibility, i.e., the extent and speed of symptom development. Alternatively, the
A

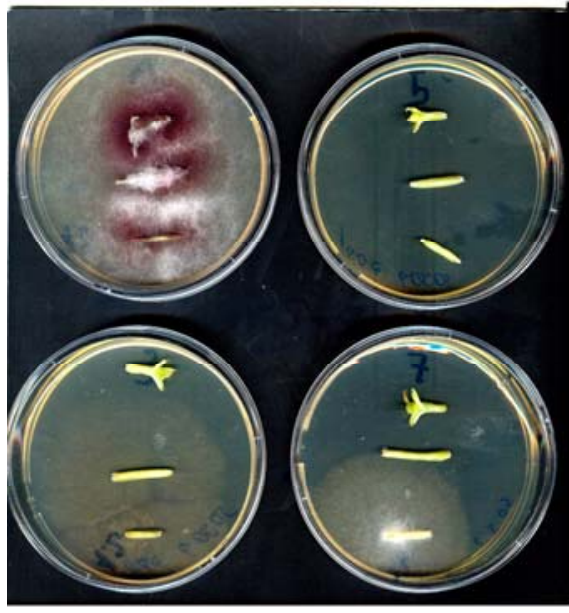

B

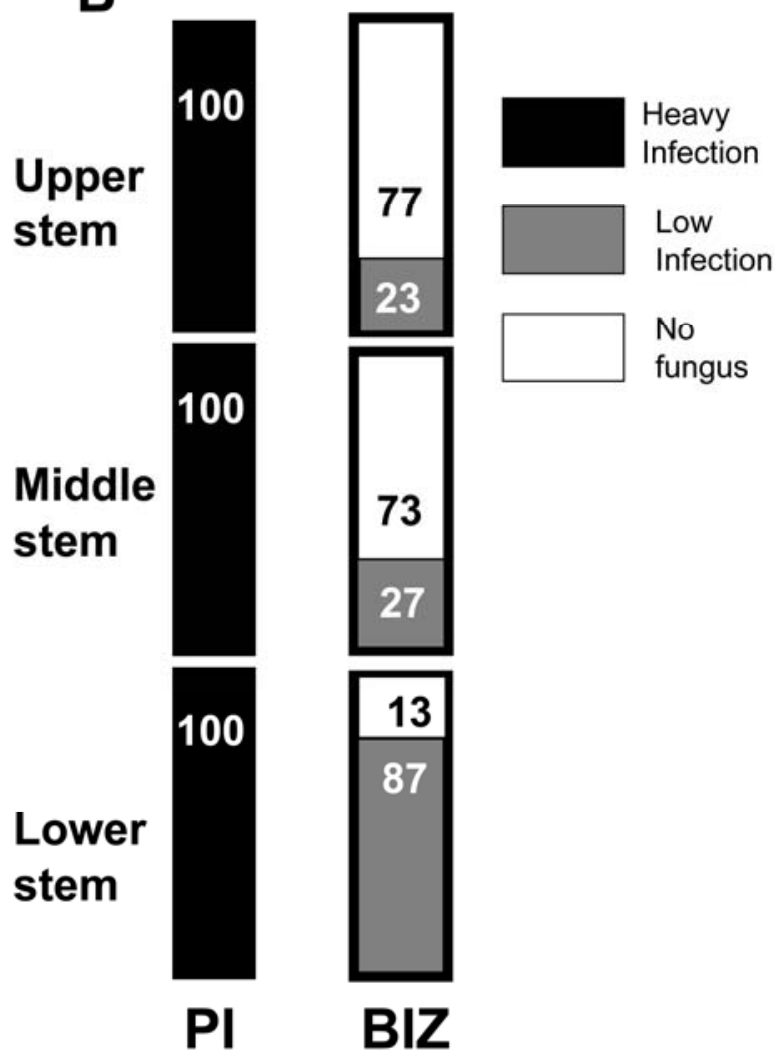

Fig. 5. Isolation of Fusarium oxysporum f. sp. melonis race 1.2 from inoculated plants. Surface-sterilized segments from PI 414723 (PI) and BIZ plants 21 days after inoculation were placed on potato dextrose agar (PDA) medium for 7 days. Control plates were prepared from noninoculated plants and remained clean (not shown). In each plate, the upper hypocotyl segment, the mid-hypocotyl, and a lower hypocotyl segment are shown from top to bottom. A, Top left plate: PI 414723. Other three plates: BIZ. Note lower density of mycelium emerging in two of the BIZ plates, while the third plate (top right) is fungus-free. B, Proportion of stem segments that were colonized by the fungus. Black: segments that gave rise to dense fungal colony; gray: segments that gave rise to low-density colonies; white: fungus-free segments. 
two main genes could interact with additional quantitative genes that modulate the strength of the response in susceptible progeny. QTL analysis of FOM 1.2 resistance, using a set of $\mathrm{F}_{3}$ families derived from the cross PI $414723 \times \mathrm{BIZ}$, is underway in our laboratory, in order to provide molecular markers for effective selection of this trait and to better elucidate its genetic control.

\section{ACKNOWLEDGMENTS}

We thank Jaacov Katan of the Hebrew University of Jerusalem for kindly supplying the fungal strain for this study and for useful discussions and review of the manuscript. We thank Ilan Levin from the Agricultural Research Organization, Israel, for helpful advice regarding the statistical analyses and critical reading of this manuscript. We also thank Zeraim Gedera Inc. for permission to use the genetic material described in this research.

\section{LITERATURE CITED}

1. Burger, Y., Katzir, N., Tzuri, G., Portnoy, V., Saar, U., Shriber, S., Perl-Treves, R., and Cohen, R. 2003. Variation in the response of melon genotypes to Fusarium oxysporum f. sp. melonis race 1 determined by inoculation tests and molecular markers. Plant Pathol. 52:204211.

2. Campbell, C. L., and Madden, L. V. 1990. Introduction to Plant Disease Epidemiology. John Wiley \& Sons, New York.

3. Chen, X. M., and Line, R. F. 1999. Recessive genes for resistance to Puccinia striiformis $\mathrm{f}$. sp. hordei in barley. Phytopathology 89:226232.

4. Cohen, R., Katan, T., Katan, J., and Cohn, R. 1989. Occurrence of Fusarium oxysporum $\mathrm{f}$. sp. melonis race 1.2 on muskmelon in Israel. Phytoparasitica 17:319-322.

5. Danin-Poleg, Y., Burger, Y., Schreiber, S., Katzir, N., and Cohen, R. 1999 Identification of the gene for resistance to Fusarium wilt races 0 and 2 in Cucumis melo Dulce. Cucurb. Genet. Coop. Rep. 22:19-20.

6. Danin-Poleg, Y., Tadmor, Y., Tzuri, G., Reis, N., Hirschberg, J., and Katzir, N. 2002. Construction of a genetic map of melon with molecular markers and horticultural traits, and localization of genes associated with ZYMV resistance. Euphytica 125:373-384.

7. Downie, N. M., and Heath, R. H. 1983. Basic
Statistical Methods. 5th ed. Harper and Row Publishers, New-York.

8. Ficcadenti, N., Sestili, S., Annibali, S., and Campaneli, G. 2002. Resistance to Fusarium f. sp. melonis Race 1.2 in melon lines Nad-1 and Nad-2. Plant Dis. 86:897-900.

9. Freeman, S., Zveibil, A., Vintal, H., and Maymon, M. 2002. Isolation of nonpathogenic mutants of Fusarium oxysporum f. sp. melonis for biological control of Fusarium wilt in cucurbits. Phytopathology 92:164-168.

10. Gordon, T. R., and Okamoto, D. 1990. Colonization of crop residue by Fusarium oxysporium f. sp. melonis and species of Fusarium. Phytopathology 80:381-386.

11. Gordon, T. R., Okamoto, D., and Jacobson, D. J. 1989. Colonization of muskmelon and nonsusceptible crops by Fusarium oxysporum $\mathrm{f}$. sp. melonis and other species of Fusarium. Phytopathology 79:1095-1100.

12. Horev, C. 2002. Grafted melons for controlling Fusarium wilt caused by Fusarium oxysporum f. sp. melonis: Horticultural and pathological aspects. M.Sc. thesis. Hebrew University of Jerusalem.

13. Katan, T., Katan, J., Gordon, T. R., and Pozniak, D. 1994. Physiologic races and vegetative compatibility groups of Fusarium oxysporum f. sp. melonis in Israel. Phytopathology 84:153-157.

14. Lee, J. M. 1994. Cultivation of grafted vegetables I. Current status grafting methods and benefits. HortScience 29:235-239.

15. Martyn, R. D., and Gordon, T. R. 1996. Fusarium wilt of melon. Pages 14-15 in: Compendium of Cucurbit Diseases. T. A. Zitter D. A. Hopkins, and C. H. Thomas, eds. American Phytopathological Society, St. Paul, MN.

16. McCreight, J. D., Bohn, G. W., and Kinshaba, A. N. 1992 "Pedigree" PI414723 melon. $\mathrm{Cu}-$ curb. Genet. Coop. Rep. 15:51-52.

17. Paterson, A. H., Saranga, Y., Menz, M., Jiang, C. X., and Wright, R. J. 2003. QTL analysis of genotype $\times$ environment interactions affecting cotton fiber quality. Theor. Appl. Genet. 106:384-396

18. Perchepied, L., Dogimont, C., and Pitrat, M. 2005. Strain-specific and recessive QTLs involved in the control of partial resistance to Fusarium oxysporum f. sp. melonis race 1.2 in a recombinant inbred line population of melon. Theor. Appl. Genet. 111:431-438.

19. Perchepied, L., and Pitrat, M. 2004. Polygenic inheritance of partial resistance to Fusarium oxysporum f. sp. melonis race 1.2 in melon.
Phytopathology 94:1331-1336.

20. Perin, C., Hagen, S., De Conto, V., Katzir, N., Danin-Poleg, Y., Portnoy, V., Baudracco-Arnas, S., Chadoeuf, J., Dogimont, C., and Pitrat, M. 2002. A reference map of Cucumis melo based on two recombinant inbred line populations. Theor. Appl. Genet. 104:1017-1034.

21. Pimentel, C., Davey, P. A., Juvik, J. A., and Long, S. P. 2005. Gene loci in maize influencing susceptibility to chilling dependent photoinhibition of photosynthesis. Photosyn Res. 85:319-326.

22. Pitrat, M. 1991. Linkage groups in Cucumis melo L. J. Hered. 82:406-411.

23. Risser, G. 1973. Étude de l'héredité de la résistance du melon (Cucumis melo) aux races 1et 2 de Fusarium oxysporum f. sp. melonis. Ann. Amelior. Plantes 23:259-263.

24. Risser, G. 1987. Controversy on resistance to Fusarium wilt in 'Perlita' (Cucumis melo L.). Cucurbit. Genet. Coop. Rep. 10:60-61.

25. Risser, G., Banihashemi, Z., and Davis, D. W 1976. A proposed nomenclature of Fusarium oxysporum f. sp. melonis races and resistance genes in Cucumis melo. Phytopathology 66:1105-1106.

26. Risser, G., and Rode, J. C. 1973. Breeding for resistance to Fusarium. oxysporum f. sp. melonis. Pages 37-39 in: Eucarpia: La Sélection du Melon. G. Risser, ed. INRA, MontfavetAvingnon, France.

27. Sherf, A. F., and Macnab, A. A. 1986. Fusarium wilt of muskmelon. Pages 334-337 in Vegetable Diseases and Their Control. 2nd ed. John Wiley \& Sons, New York.

28. Shifriss, W. O. 1947. Developmental reversal of dominance in Cucurbita pepo. Proc. Am. Soc. Hortic. Sci. 50:330-346.

29. Silberstein, L., Kovalski, I., Brotman, Y., Perin, C., Dogimont, C., Pitrat, M., Klingler, J., Thompson, G., Portnoy, V., Katzir, N., and Perl-Treves, R. 2003. Linkage map of Cucumis melo including phenotypic traits and sequencecharacterized genes. Genome 46:761-773.

30. Traka-Mavrona, E., Koutsika-Sotiriou, M., and Pritsa, T. 2000. Response of squase (Cucurbita spp.) as rootstock for melon (Cucumis melo L.) Sci. Hortic. 83:353-362.

31. Zink, F. W. 1983. Reaction of muskmelon germ plasm to inoculation with Fusarium oxysporum f. sp. melonis race 2. Plant Dis. 67:1251-1255.

32. Zink, F. W., and Gubler, W. D. 1985. Inheritance of resistance in muskmelon to Fusarium wilt. J. Am. Soc. Hortic. Sci. 110:600-604. 